\title{
Potential-Dependence of the Aqueous Oxidation of Alloy 22 in Simulated Concentrated Well Water
}

\author{
P. J. Bedrossian
}

November 1, 2000

U.S. Department of Energy

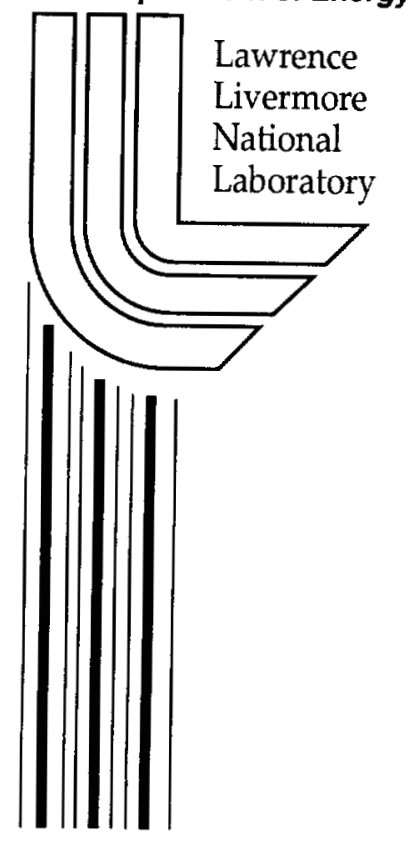




\section{DISCLAIMER}

This document was prepared as an account of work sponsored by an agency of the United States Government. Neither the United States Government nor the University of California nor any of their employees, makes any warranty, express or implied, or assumes any legal liability or responsibility for the accuracy, completeness, or usefulness of any information, apparatus, product, or process disclosed, or represents that its use would not infringe privately owned rights. Reference herein to any specific commercial product, process, or service by trade name, trademark, manufacturer, or otherwise, does not necessarily constitute or imply its endorsement, recommendation, or favoring by the United States Government or the University of California. The views and opinions of authors expressed herein do not necessarily state or reflect those of the United States Government or the University of California, and shall not be used for advertising or product endorsement purposes.

This work was performed under the auspices of the U.S. Department of Energy by the University of California, Lawrence Livermore National Laboratory under Contract No. W-7405-Eng-48.

This report has been reproduced directly from the best available copy.

Available electronically at http://www.doc.gov/bridge

Available for a processing fee to U.S. Department of Energy

And its contractors in paper from

U.S. Department of Energy

Office of Scientific and Technical Information

P.O. Box 62

Oak Ridge, TN 37831-0062

Telephone: (865) 576-8401

Facsimile: (865) 576-5728

E-mail: reports@adonis.osti.gov

Available for the sale to the public from

U.S. Department of Commerce

National Technical Information Service

5285 Port Royal Road

Springfield, VA 22161

Telephone: (800) 553-6847

Facsimile: (703) 605-6900

E-mail: orders@ntis.fedworld.gov

Online ordering: http://www.ntis.gov/ordering.htm

OR

Lawrence Livermore National Laboratory

Technical Information Department's Digital Library

http://www.llnl.gov/tid/Library.html 


\title{
Potential-Dependence of the Aqueous Oxidation of Alloy 22 in Simulated Concentrated Well Water
}

\author{
Peter J. Bedrossian \\ Division of Materials Science and Technology \\ and \\ Yucca Mountain Site Characterization Program, \\ Lawrence Livermore National Laboratory, Livermore CA 94551
}

\begin{abstract}
Using x-ray photoemission spectroscopy (XPS), we have identified elemental oxidation state shifts in the passive films of coupons of Alloy 22 polarized anodically at various potentials below the passive-transpassive transition in $90 \mathrm{C}$ in a concentrated version of J-13 water. The data suggest a general trend toward higher oxidation states and a narrowing in the distribution of oxidation states of $\mathrm{Ni}, \mathrm{Cr}$, and Mo with increasing potential. The relative proportion of Mo in the passive film increases at the highest potentials tested.
\end{abstract}

\section{Introduction}

Because metal corrosion processes all involve breakdown of the passive film, an understanding of the thermodynamic stability of the passive film under relevant environmental conditions is essential to the development of a capability for modeling corrosion resistance of a metal. In a multi-component alloy such as Alloy 22, the passive film incorporates all of the elements of the base metal, and the individual elemental oxidation states and atomic concentrations within the passive film will, in general, be dependent on environmental conditions such as temperature, $\mathrm{pH}$, and the concentrations of ionic species in the aqueous environment. Cyclic voltammetry is a powerful tool for associating environmental conditions with general properties such as passivity and dissolution, and as such it should be the starting point for analysis of passive films. However, cyclic voltammetry by itself does not reveal the composition of the passive film or the interaction of its constituents with the ions in its aqueous environment. An extensive body of cyclic voltammograms has already been collected for the Yucca 
Mountain Project. It is the intention of this study to elucidate features already observed in that work, but not to repeat the previous cyclic voltammetry. [1]

We have undertaken a systematic study associating features observed in voltammograms with specific changes in the nature of the passive film on Alloy 22 . Here we report the initial set of results of this study, documenting the evolution of the oxidation states of constituent elements in the passive film on Alloy 22 with increasing potential in 90C Simulated Concentrated Well Water (SCW). To our knowledge, this work represents the first such study within the Yucca Mountain complex.

Core-level XPS is a surface sensitive technique which is widely used for the identification of oxidation states of materials. In general, higher oxidation states of metal atoms result in upward shifts of core-level energies. It is the goal of this work to identify any such shifts associated with the main constituent elements of Alloy 22 under aqueous polarization. Two points must be considered in the interpretation of ex situ XPS data from aqueous corrosion experiments:

1) The region of the surface sampled has a diameter of approximately $2 \mathrm{~mm}$, so the spectra presented here give no information on the distribution of elements or oxides on a surface. Elements may or may not be distributed evenly. This technique would not detect spatial inhomogeneities, such as grain boundary segregation.

2) Because the XPS measurement requires removing a sample from its aqueous environment, drying it, and placing it in an ultrahigh vacuum spectrometer, hydrated species formed on the surface will likely be transformed to their dehydrated equivalents. (For example, $\mathrm{Cr}(\mathrm{OH})_{3}$ would be likely to transform to $\mathrm{Cr}_{2} \mathrm{O}_{3}$.)

A standard tabulation of chemical shifts in XPS is published by PHI. [2] All spectra shown below are normalized in order to facilitate comparison of electron binding energies. We have not performed quantitative XPS to determine relative concentrations of the elements.

\section{Method}

All coupons of Alloy 22 [3] tested were metallographically polished to a finish of less than 2nm rms, as measured with AFM, and then degreased. [4] Each sample was

${ }^{1}$ J. Farmer, et al., Waste Package Process Modeling Report for EDA II., Ymp ANL-EBSMD-000003 Rev O0D (2000). See Figure 14 for reference voltammogram showing anodic oxidation peak in SCW.

2 J. Moulder, et al., ed., Handbook of X-ray Photoelectron Spectroscopy, (Eden Prarie, MN: Physical Electronics, 1992).

${ }^{3}$ Metal Samples Corporation.

${ }^{4}$ P. Bedrossian, "Specimen Preparation for Atomic Force Microscopy, " YMP TIP-E-2071, Rev. 0 (1999). 
then polarized in a standard electrochemical cell [5] by raising the applied potential from the open circuit potential to a predetermined potential relative to a saturated $\mathrm{Ag} / \mathrm{AgCl}$ reference electrode at a rate of $1200 \mathrm{mV} / \mathrm{hr}$. The cell was aerated during polarization with dry nitrogen derived from the boiloff of liquid nitrogen. Otherwise, the polarization followed the standard procedures described in the NACE manual. [6] Following polarization, the sample was removed from the cell, washed with deionized water, dried, and degreased again.

XPS measurements were performed with a PHI 5400 spectrometer, using $\mathrm{Mg} \mathrm{K \alpha}$ radiation.

All of the XPS measurements were performed on samples polarized at a temperature of $90 \mathrm{C}$ in an aqueous environment consisting of Simulated Concentrated Well Water (SCW), with a $\mathrm{pH}$ of 7.85. [7]

The sample numbers reported in the data below are the serial numbers originally stamped by the vendor.

\section{Results}

The first five figures below present a compilation of XPS spectra showing the ranges associated with the $\mathrm{Ni} 2 \mathrm{p}, \mathrm{Mo} 3 \mathrm{~d}, \mathrm{Cr} 2 \mathrm{p}, \mathrm{O} 1 \mathrm{~s}$, and $\mathrm{C} 1 \mathrm{~s}$ peaks, respectively. We were unable to resolve the $\mathrm{W} 4 \mathrm{f}$ lines satisfactorily, because of overlap with an Fe Auger line. There is a total of six spectra in each plot. The first, trace, labelled in black was acquired from an unexposed region around the rim of coupon DEA987. Because it was outside the aqueous environment, that spectrum is used as a reference. The rest of the traces were acquired from samples polarized to various potentials around the anodic oxidation peak identified previously. [1] The DEA483 sample, identified with a red trace, was polarized well below the peak, in a region where the current was nearly insensitive to applied voltage. The DEA987 coupon, identified with a brown trace, was polarized just below the apex of the anodic peak, and the DEA986 coupon, identified with a yellow trace, was polarized just above the apex. The DEA404 coupon, identified with a green trace, was polarized well above the apex, were the current still decreased with increasing voltage. Finally, the DEA405 coupon was polarized still farther above the apex, where the current changed relatively little with increasing potential, and just below the onset of the passive-transpassive transition.

The potentials reported on the plots do not compare directly with one another on an absolute scale, because a change in Luggin probe led to an offset in absolute potential. Two different Luggin probes were used. The polarizations of samples DEA987 and DEA986, labelled as "Old Probe," are offset approximately $250 \mathrm{mV}$ with respect to the

\footnotetext{
${ }^{5}$ Princeton Applied Research Corporation.

${ }^{6}$ N. Thompson and J. Payer, DC Electrochemical Test Methods, (Houston, TX: NACE, 1998).

${ }^{7}$ G. Gdowski, "Formulation and Make-Up of Simulated Acidic concentrated Water (SAW), High Ionic Content Aqueous Solution," YMP TIP-CM-08-001, Rev. 0 (1997).
} 
polarizations of samples DEA403, DEA404, and DEA405, each of which is labelled as "New Probe."

None of the coupons showed signs of pitting or cracking in either optical or atomic force microscopy (AFM). However, a bluish film, which appeared progressively darker with increasing, applied potential, was visible on the polarized specimens.

\section{Nickel}

Figure 1 presents the progression of $\mathrm{Ni} 2 \mathrm{p}$ spectra. Ni spectra in this region typically show two sets of two peaks each: the $2 \mathrm{p}^{3 / 2}$ pair at the lower binding energies and the $2 \mathrm{p}^{5 / 2}$ pair at the higher binding energies. Both the unexposed sample and the sample polarized well below the anodic peak (DEA403) show predominantly elemental $\mathrm{Ni}$, with some oxide. The onset of the anodic peak (DEA987) is associated with a reversal of these relative proportions, in which the oxide dominates the elemental component. Up to this point, the broadness of the oxide peaks suggests that more than one oxide is present on the surface. Above the apex of the anodic peak (DEA986, DEA404, and DEA405), the elemental component has disappeared, and the spectrum is consistent with an oxidation state of +3 for $\mathrm{Ni}$.

\section{Molybdenum}

Figure 2 presents the progression of Mo $3 \mathrm{~d}$ spectra. In general, each component should give rise to a pair of peaks: the larger, $3 \mathrm{~d}^{3 / 2}$ peak at the lower binding energy, and the smaller, $3 \mathrm{~d}^{5 / 2}$ peak at the higher binding energy. The unexposed surface shows a mixture of elemental molybdenum and at least two other, distinct oxidation states of Mo. Sampes DEA987 and DEA986 show progressive diminution of the elemental and 2+ peaks and enhancement of the $3+$ peak. Above the apex of the anodic oxidation peak, (DEA986, DEA404, and DEA405), the elemental Mo component has diminished to an undetectable level, and the relative concentration of Mo in the 3+ oxidation state increases steadily in the passive film.

\section{Chromium}

Figure 3 presents the $\mathrm{Cr} 2 \mathrm{p}$ spectral region. Each component should give rise to two, sharp peaks: the $2 \mathrm{p}^{3 / 2}$ peak at lower binding energies, and the $2 \mathrm{p}^{1 / 2}$ peak at higher binding energies. Oxidized chromium dominates in all spectra, and elemental $\mathrm{Cr}$ has disappeared below the detection limit for applied potentials above the anodic peak. The instrument used here is unable to distinguish $\mathrm{Cr}^{3+}$ from $\mathrm{Cr}^{6+}$ definitively.

\section{Oxygen}

Figure 4 presents the progression of $O 1$ s spectra. The progressive sharpening of the peak indicates a narrowing in the range of oxidation states of consituent elements with increasing, applied potential. This observation is consistent with the previous figures. The overall increase in magnitude of the peaks with increasing, applied potential suggests growth of an oxide film.

\section{Carbon}

Figure 5 presents the progression of $\mathrm{C} 1 \mathrm{~s}$ spectra. The hydrocarbon portion decreases steadily, suggesting a decrease in surface contamination. Meanwhile, there is 
little change in $\mathrm{C}-\mathrm{O}$ and $\mathrm{C}=\mathrm{O}$ contributions, suggesting that carbonate absorption has not taken place.

\section{Discussion}

At the lowest potentials tested, chromium has oxidized the most, nickel the least, and molybdenum is intermediate. Qualitatively, this trend seems reasonable on the basis of the published, equilibrium Pourbaix diagrams. [8] According to the published diagrams, at $\mathrm{pH}=7.85$ in solutions containing chloride ions, chromium has an oxide which is thermodynamically stable at the lowest potential of the three elements, with molybdenum oxide being stable at the next lowest potential.

The progression of specific oxidation states also seems consistent with the published, Pourbaix diagrams. For example, the dominant oxide of $\mathrm{Cr}$ at $\mathrm{pH}=7.85$ has $\mathrm{Cr}$ in an oxidation state of +3 , consistent with our findings in Figure 3. Mo, on the other hand, progresses from elemental molybdenum to $\mathrm{MoO}_{2}$ and then to oxides with a Mo oxidation state of +6 , and a similar progression appears in Figure 2 .

In summary, potentials exceeding the anodic anodic oxidation peak lead to predominance in the passive film of oxides of $\mathrm{Ni}, \mathrm{Cr}$, and $\mathrm{Mo}$ with high oxidation states. In addition, Mo concentrations in the passive film continue to increase with increasing, applied potential beyond the anodic oxidation peak, with the caveat that the distribution of these elements may be non-uniform.

At this point, we are not yet in a position to conclude whether the observed dependence of the elemental oxidation states on applied potential is a cause, a consequence, or only coincidentally related to the anodic oxidation peak observed in cyclic voltammetry. In order to make this determination, we suggest performing similar XPS measurements on coupons polarized under similar conditions of $\mathrm{pH}$ and temperature but with different water compositions. Figure 6 displays voltage ramps obtained from three different coupons of Alloy 22 polarized in solutions with $\mathrm{pH}=7.85$. Of these, only the SCW solution gives rise to a distinct, anodic oxidation peak. The peak was suppressed in the other two curves by starting with Simulated Acidified Well Water (SAW) and raising the $\mathrm{pH}$ to 7.85 by adding either $\mathrm{NaOH}$ or a combination of $\mathrm{NaOH}$ and $\mathrm{NaHCO}_{3}$. The suppression of the anodic oxidation peak in those cases suggests that the anodic peak itself is affected not only by $\mathrm{pH}$ but also by the concentration of some other species, such as the bicarbonate ion. Yet, the $\mathrm{C} 1 \mathrm{~s}$ spectra in Figure 5 show no particular protection by carbonate or bicarbonate species even under conditions which give rise to the anodic oxidation peak. Further work in this area is necessary to elucidate the interaction of water chemistry and surface chemistry conclusively.

\section{Acknowledgements}

The author is grateful to R. Kershaw for sample preparation, to A. Nelson and C. Evans for XPS data collection, and to D. Fix for sample polarization. Work was

\footnotetext{
${ }^{8}$ M. Pourbaix, Atlas of Electrochemical Equilibria in Aqueous Solutions, (Houston, TX: NACE, 1974)
} 
performed at University of California/Lawrence Livermore National Laboratory under the auspices of the US DOE under Contract W7405-Eng-48 and was supported by the Yucca Mountain Site Characterization Project. The work reported here was conducted under Activity Plan AP-E-20-69 and documented in YMP SN 00427.

\section{List of Figures}

Figure 1: XPS Spectra showing the Ni $2 p$ lines on Alloy 22 following anodic polarizations, as indicated.

Figure 2: XPS Spectra showing the Mo 3d lines on Alloy 22 following anodic polarizations, as indicated.

Figure 3: XPS Spectra showing the $\mathrm{Cr} 2 \mathrm{p}$ lines on Alloy 22 following anodic polarizations, as indicated.

Figure 4: XPS Spectra showing the $O 1$ s lines on Alloy 22 following anodic polarizations, as indicated.

Figure 5: XPS Spectra showing the $\mathrm{C} 1 \mathrm{~s}$ lines on Alloy 22 following anodic polarizations, as indicated.

Figure 6: Voltammograms showing polarization of Alloy 22 in three distinct solutions of $\mathrm{pH}=7.85$, derived from concentrated variants of $\mathrm{J} 13$ water. 


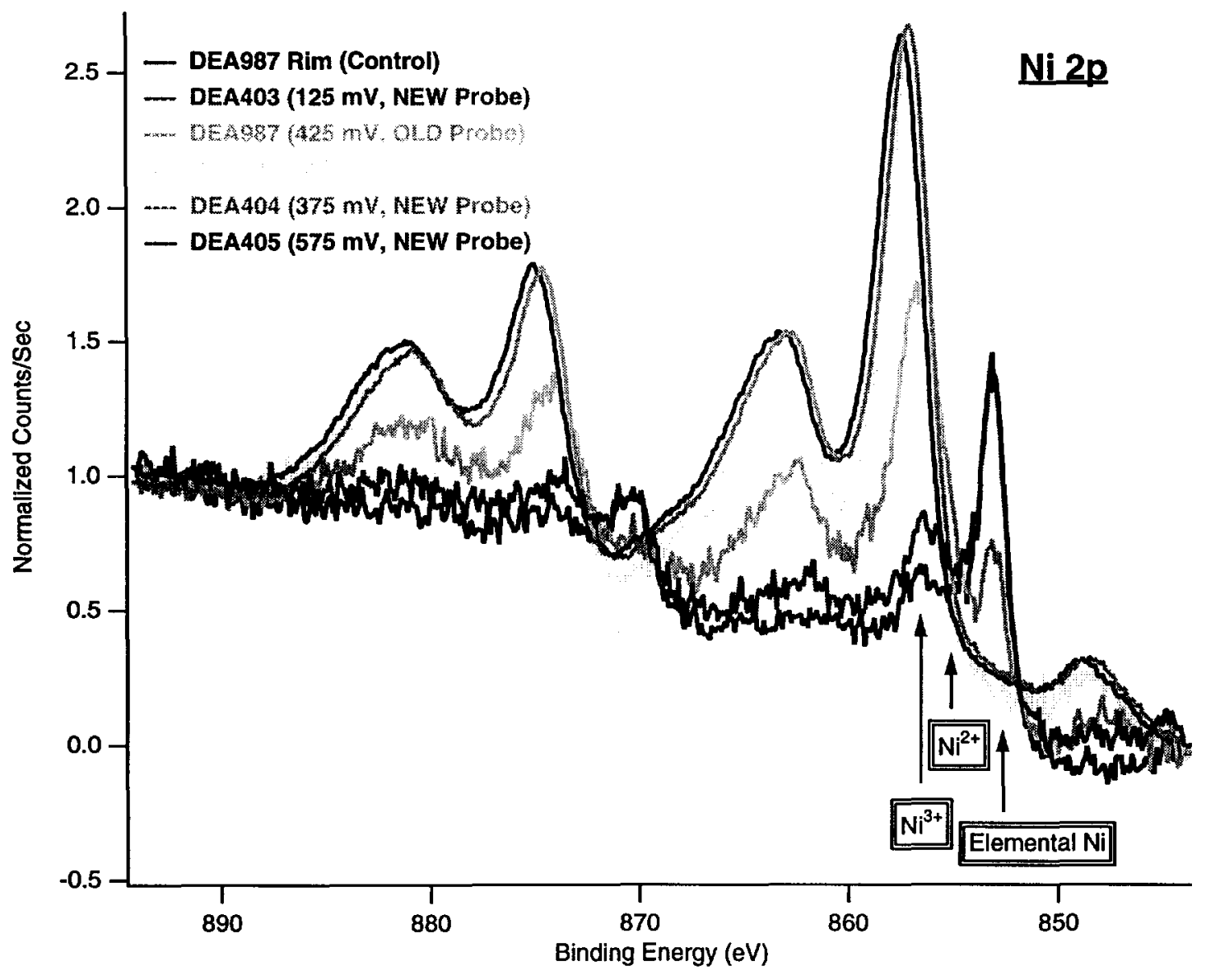

Figure 1: XPS Spectra showing the Ni 2p lines on Alloy 22 following anodic polarizations, as indicated. 


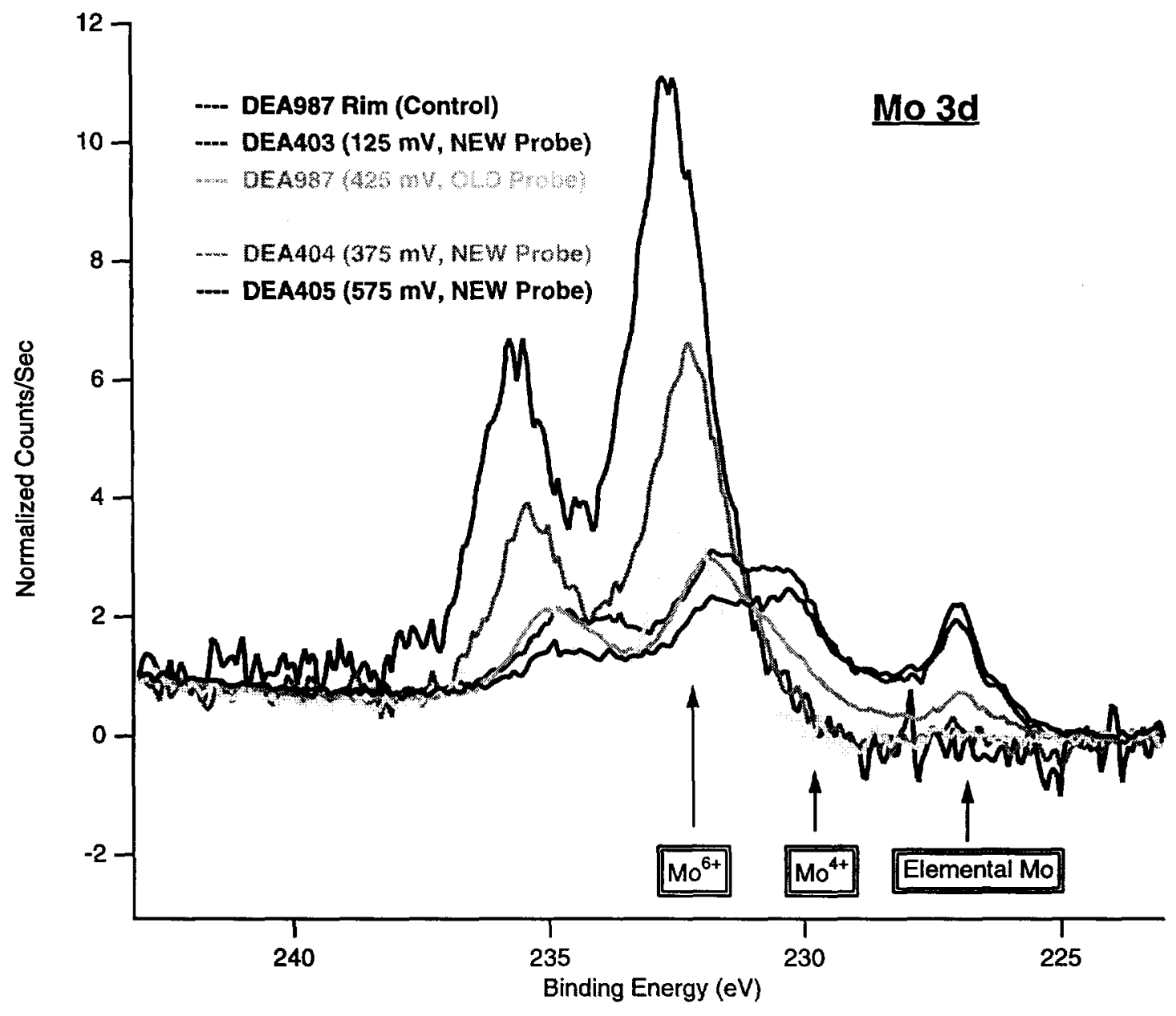

Figure 2: XPS Spectra showing the Mo 3d lines on Alloy 22 following anodic polarizations, as indicated. 
-pąeว!pu! se 'suǫ̣ez!̣ejod

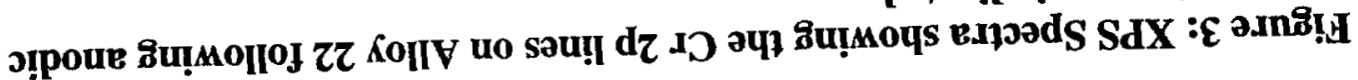
^а) К6ıачэ 6u!pu!g

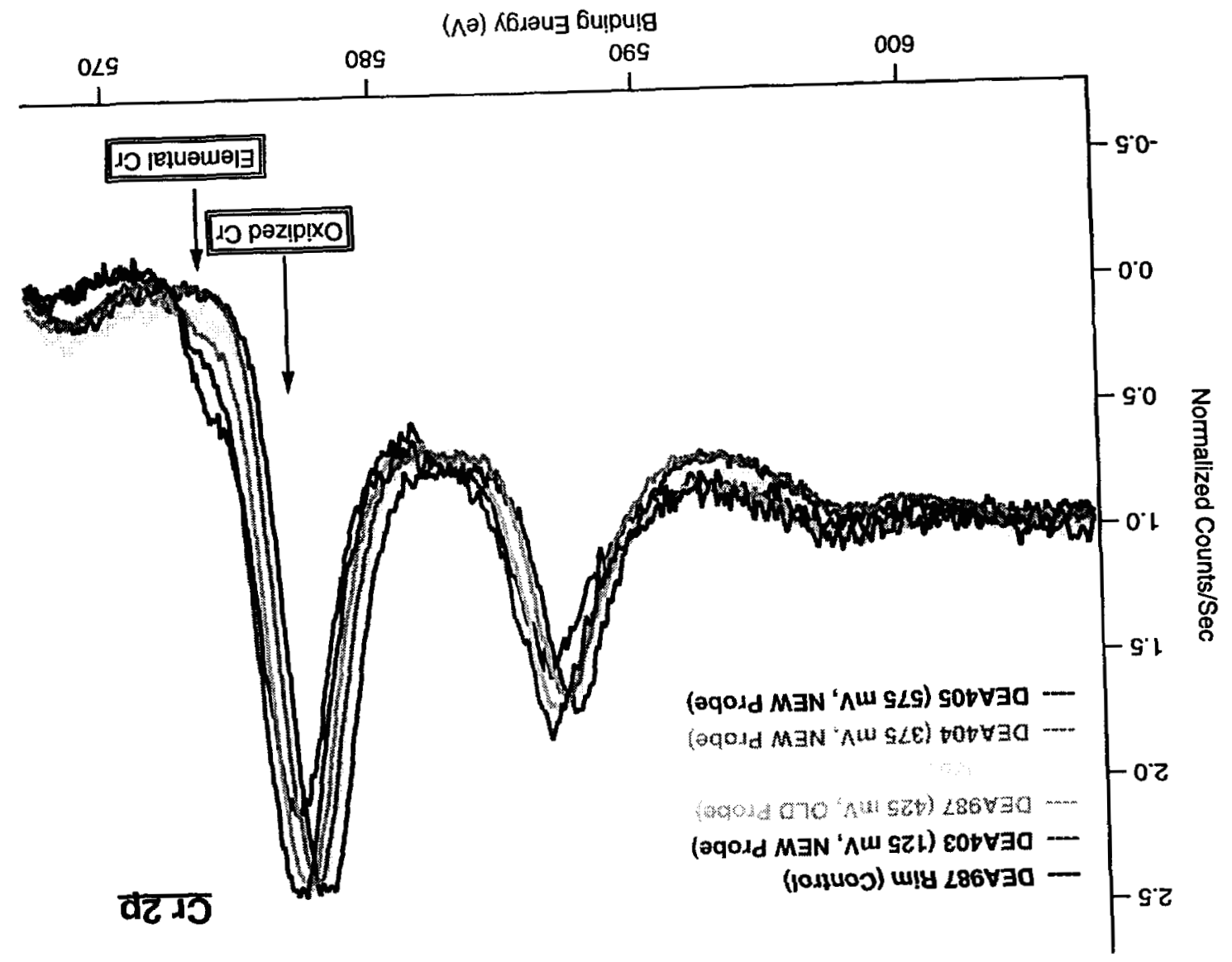




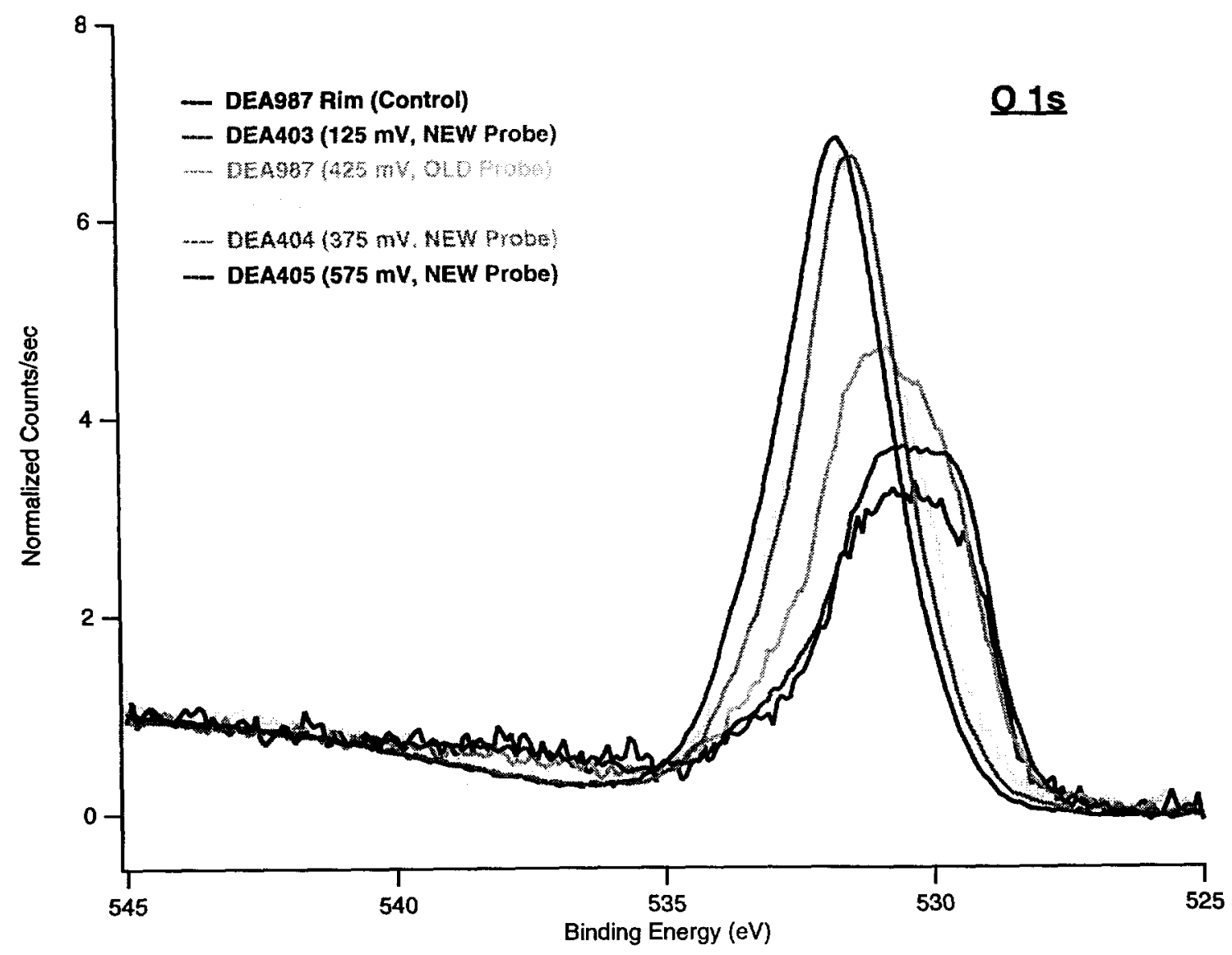

Figure 4: XPS Spectra showing the $O 1$ s lines on Alloy 22 following anodic polarizations, as indicated. 


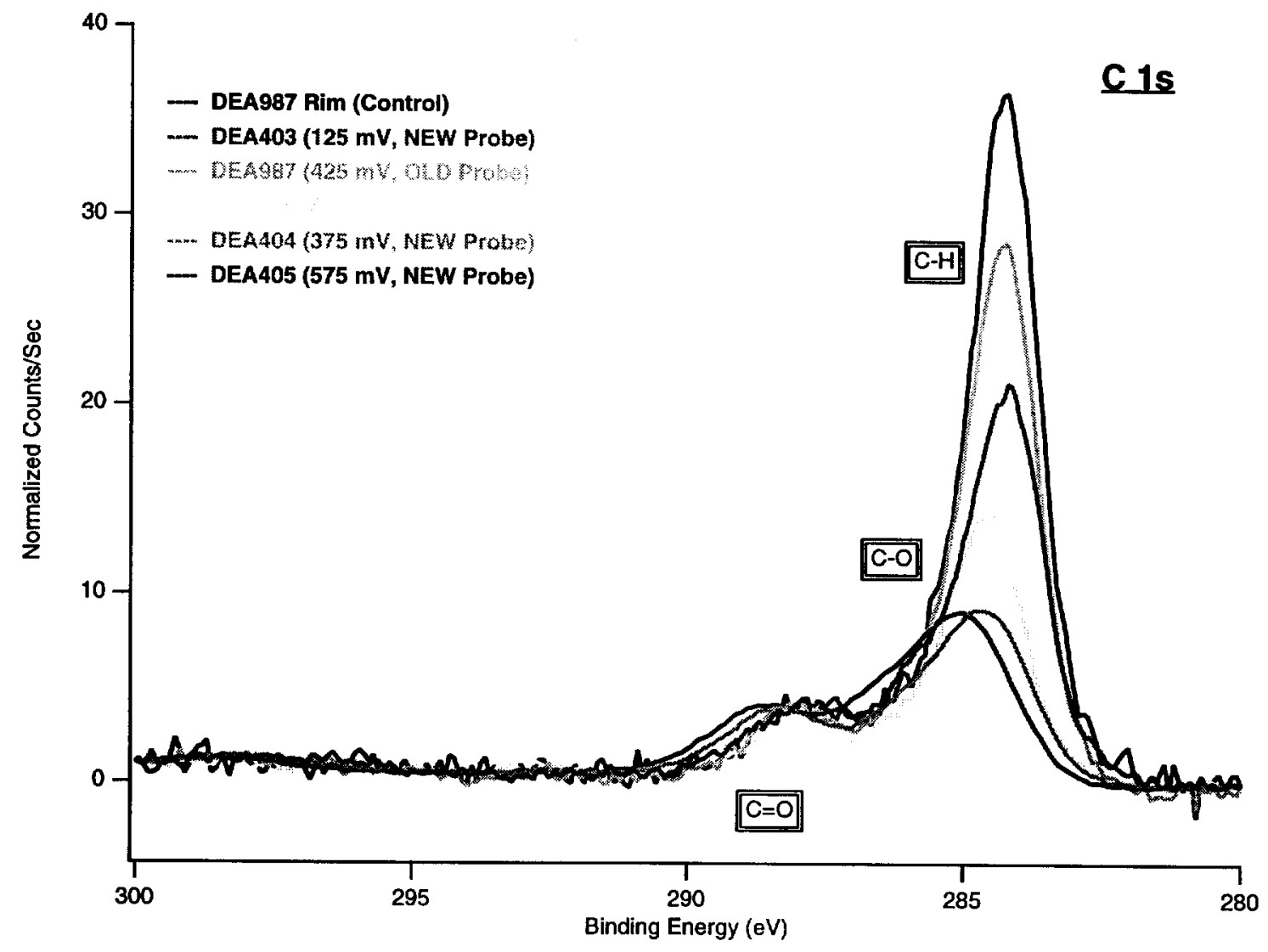

Figure 5: XPS Spectra showing the C 1s lines on Alloy 22 following anodic polarizations, as indicated. 


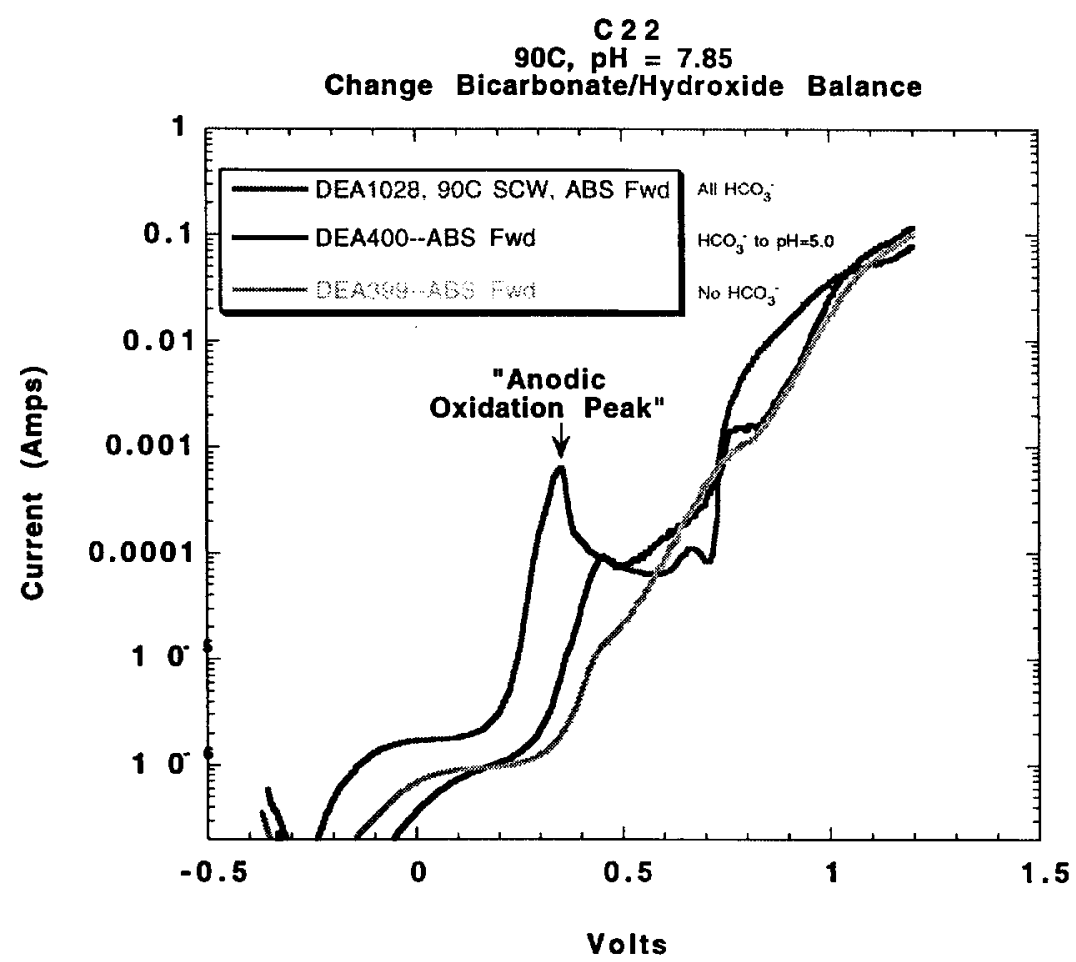

Figure 6: Voltammograms showing polarization of Alloy 22 in three distinct solutions of $\mathrm{pH}=\mathbf{7 . 8 5}$, derived from concentrated variants of $\mathrm{J13}$ water. 